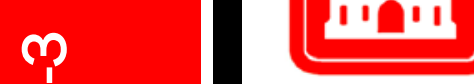

US Army Corps

of Engineers $\mathrm{B}_{\circledast}$

Engineer Research and

Development Center

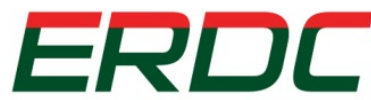

INNOVATIVE SOLUTIONS for a safer, better world

\title{
Testing of the KRIA lonizing Water Treatment System for Waters Contaminated with Diesel, PCBs, and Nutrients (Nitrogen Forms)
}

Victor F. Medina, Agnes Morrow, Catherine C. Thomas,

February 2016

and Roy Wade

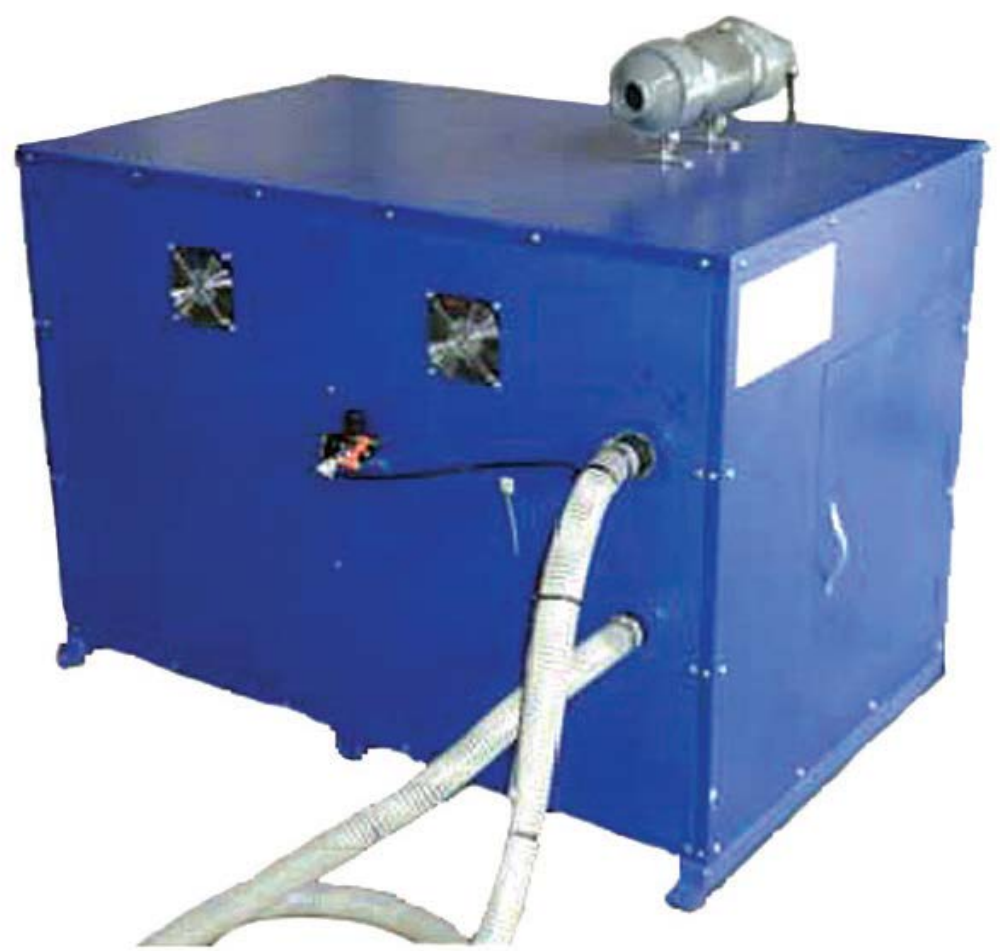


The U.S. Army Engineer Research and Development Center (ERDC) solves the nation's toughest engineering and environmental challenges. ERDC develops innovative solutions in civil and military engineering, geospatial sciences, water resources, and environmental sciences for the Army, the Department of Defense, civilian agencies, and our nation's public good. Find out more at www.erdc.usace.army.mil.

To search for other technical reports published by ERDC, visit the ERDC online library at http://acwc.sdp.sirsi.net/client/default. 
ERDC/EL TR-16-3

February 2016

\section{Testing of the KRIA lonizing Water Treatment System for Waters Contaminated with Diesel, PCBs, and Nutrients (Nitrogen Forms)}

Victor F. Medina, Agnes Morrow, Catherine C. Thomas, and Roy Wade

Environmental Laboratory

U.S. Army Engineer Research and Development Center 3909 Halls Ferry Road

Vicksburg, MS 39180-6199

Final report

Approved for public release; distribution is unlimited. 


\section{Abstract}

This project evaluated the KRIA water treatment system (also know under the trade name ECOSOAR) for treatment of three environmental contaminants: diesel fuel, PCBs (arochlor 1254) and nutrients (nitrogen forms). The KRIA water treatment system works by charging water with the superoxide radical $\left(\mathrm{O}_{2}{ }^{-}\right)$, which is electrochemically generated from oxygen in the atmosphere. At the injection site, both cavitation and microbubble reactions may also occur. A review of the literature indicates that superoxide is a relatively weak radical, but it can work both oxidatively and reductively. A review of the literature also showed that superoxide can transform chlorinated solvents and microcystin (a toxin associated with algae). Studies of the KRIA yielded promising results, but most of these studies lacked sufficient control to isolate variables, possibly casting doubt on the exact nature of the mechanism. Background studies were conducted to evaluate the KRIA's effect on water. The KRIA charged water for 135 minutes and was compared to a control in which the superoxide valve was turned off. It was found that the superoxide charging resulted in elevated (approximately threefold) levels of oxygen, which led to the water being supersaturated (by approximately 300\%). Conductivity was also increased, presumably due to the addition of charged oxygen species into the water. These elevated levels persisted for at least 24 hours after the charging, suggesting that the effect was persistent. The team also documented elevated concentrations of superoxide ion after charging. Treatment of diesel resulted in a 58\% increase in removal compared to the control reactor, and this was statistically significant. Treatment of PCBs resulted in a $20 \%$ increase in removal as compared to the control, and was also statistically significant. Treatment of nutrients (ammonia and nitrate) did not appear to result in any changes to their respective concentrations.

DISCLAIMER: The contents of this report are not to be used for advertising, publication, or promotional purposes. Citation of trade names does not constitute an official endorsement or approval of the use of such commercial products. All product names and trademarks cited are the property of their respective owners. The findings of this report are not to be construed as an official Department of the Army position unless so designated by other authorized documents. 


\section{Contents}

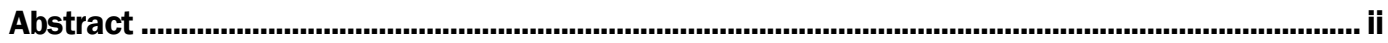

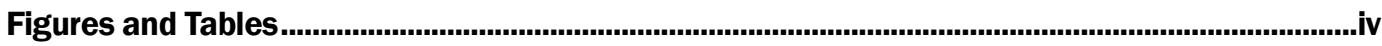

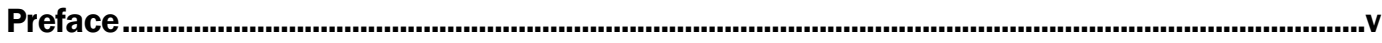

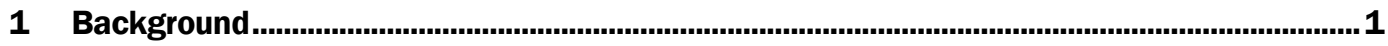

KRIA Ionizing Water Treatment System ................................................................ 1

Superoxide Radical ..................................................................................................... 1

Other potential reactions from KRIA operation ......................................................... 3

Results of Studies Provided by Premier Materials .......................................................... 4

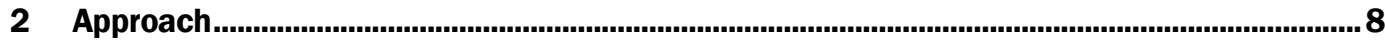

General Experimental Setup..................................................................................... 8

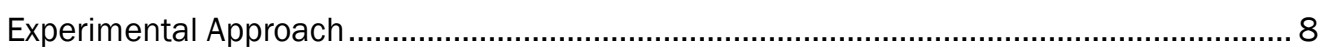

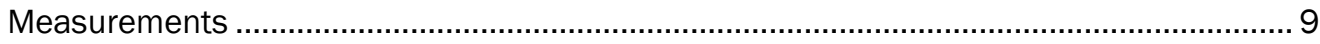

3 Results .....................................................................................................................................11

Effect on General Water Quality Parameters ........................................................... 11

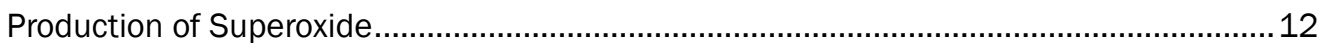

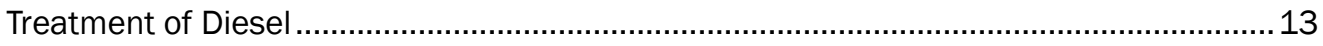

Treatment of PCBs (Arochlor 1254) .......................................................................... 14

Treatment of Nutrients as Nitrogen Forms ............................................................... 16

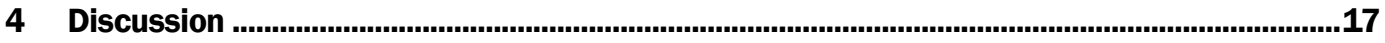

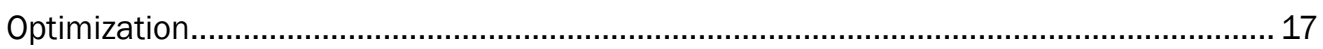

Potential Applications................................................................................................ 17

Other Factors That Might Affect Performance ........................................................... 19

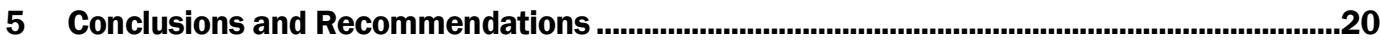

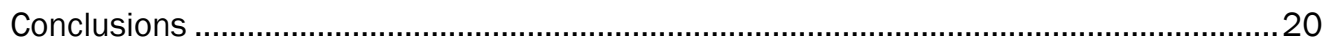

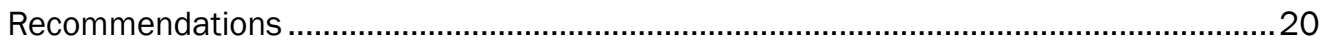

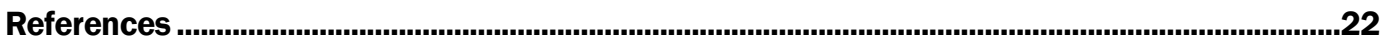

\section{Report Documentation Page}




\section{Figures and Tables}

\section{Figures}

Figure 1. Field deployment of the KRIA water treatment system (a), and KRIA in laboratory (b), recirculation pump (c), and superoxide generation system (d). 2

Figure 2. Propeller mixer (a) and on/off valve for superoxide reservoir (in "off" position, b)............... 9

Figure 3. Some of the analytical instruments used in this project. Assay plate reader (upper left) and 96 well plate used for the superoxide dimutase assay (upper right), which were used to semi-quantitatively measure superoxide concentration, and dionex ion chromatograph used for nitrate and nitrite measurements (a similar system was set up for cation measurements and used for ammonium analysis) (lower left). Water quality meter for $\mathrm{pH}$, conductivity, dissolved oxygen (DO), percent oxygen saturation (DO\%), and oxygen-reduction potential (ORP) (lower right).

Figure 4. Superoxide activity as measured using SOD assay.

Figure 5. PCB concentrations in superoxide (SO) and control reactors. TO is after spiking, T1 is one hour after KRIA operation, T2 is 2 hours, T3 is 4 hours, T4 is 24 hours, and T5 is 72 hours. Error bars represent standard deviation among triplicated samples.

Figure 6. PCB concentrations in superoxide (SO) and control reactors. TO is after spiking, T1 is one hour after KRIA operation, T2 is 2 hours, T3 is 4 hours, T4 is 24 hours, and T5 is 72 hours. Error bars represent standard deviation among triplicated samples.

\section{Tables}

Table 1. Data from study conducted at Ueno Zoo, Tokyo, Japan, 31 August 2001............................ 6

Table 2. Disinfection using ECOCLEAN solution (counts per $\mathrm{mL}$ )........................................................ 6

Table 3. Constituents tested and initial target concentrations.......................................................

Table 4. Summary of water quality parameter measurements over 135 minutes with KRIA water treatment system operation with superoxide (SO) valve open and closed. 


\section{Preface}

The work reported herein was conducted at the U.S. Army Engineer Research and Development Center (ERDC), Environmental Laboratory (EL), in Vicksburg, MS. The project was approved by the Center for the Advancement of Sustainability Innovations (CASI at CERL) and was funded by Premier Materials Technology, LLC via a cooperative research and development agreement (CRADA).

The study was conducted by Dr. Victor Medina, Agnes Morrow, and Roy Wade, all of the Environmental Engineering Branch (CEERD-EPE). The report was prepared by Dr. Victor Medina. Peer review was provided by Dr. Heather Knoteck-Smith and by Dr. Catherine C. Thomas of ERDC-EL. At the time of publication of this report, Dr. W. Andy Martin was Chief, CEERD-EPE; Warren P. Lorentz was Chief, Environmental Processes and Engineering Division; Dr. Beth Fleming was Director, EL; COL Bryan S. Green was Commander of ERDC, and Dr. J effery P. Holland was Director of ERDC. 


\section{Background}

\section{KRIA lonizing Water Treatment System}

The KRIA ionizing water treatment system is designed to be deployed into rivers, streams, lakes, and ponds (Figure 1) - although it could be effectively applied into tanks and engineered reactors as well. It has an intake where water is drawn into the reactor, and a discharge, where water is returned (Figure 1). Superoxide is produced from atmospheric air. The air is drawn into the system, and then electrochemically treated, which charges molecular oxygen into the superoxide anion (Figure 1). The method of ionization is described as "ionization by collision," and involves reaction in a magnetic field as the air is drawn through a bed of ceramic balls with reactive minerals, which are not specified (Kunio et al. 1999). The negatively charged air is then pressurized and stored in a reservoir tank. This superoxide is charged into the discharge of the system (a video showing the superoxide charging can be seen at https://www.youtube.com/watch?v=b3UJnz88Lxs\& feature=em-upload_owner). The discharge is also a key part of the treatment, as it is designed to promote reactions by cavitation and by microbubble effects in addition to superoxide reactions (Kunio et al. 1999).

\section{Superoxide Radical}

Superoxide is a term used to describe negatively changed oxygen $\left(\mathrm{O}_{2}^{-}\right)$ (Connelly et al. 2005). It is a common radical, produced from a variety of reactions. Superoxide has been described as poorly reactive and even inert (Mezyk et al. 2013). However, articles have documented significant reactions with this radical; these articles will be discussed later in this section.

There are many ways to generate the superoxide radical, and many common advanced oxidation approaches generate the superoxide radical as intermediate steps. Fenton's reactions generate superoxide radicals as an intermediate step; in fact, it is possible to modify the process to intentionally produce superoxide predominantly. For example, Watts et al. (2003) added pyrolusite (manganese oxide) to stimulate superoxide production as part of the Fenton's chemistry reaction. Superoxide can also be generated in zerovalent iron reactions (J oo et al. 2004, Katsoyiannis et al. 2008, Noubactep and Schoner 2009). Titanium dioxide $\left(\mathrm{TiO}_{2}\right)$ reactions also produce superoxide, and these radicals are considered an 
Figure 1. Field deployment of the KRIA water treatment system (a), and KRIA in laboratory (b), recirculation pump (c), and superoxide generation system (d).
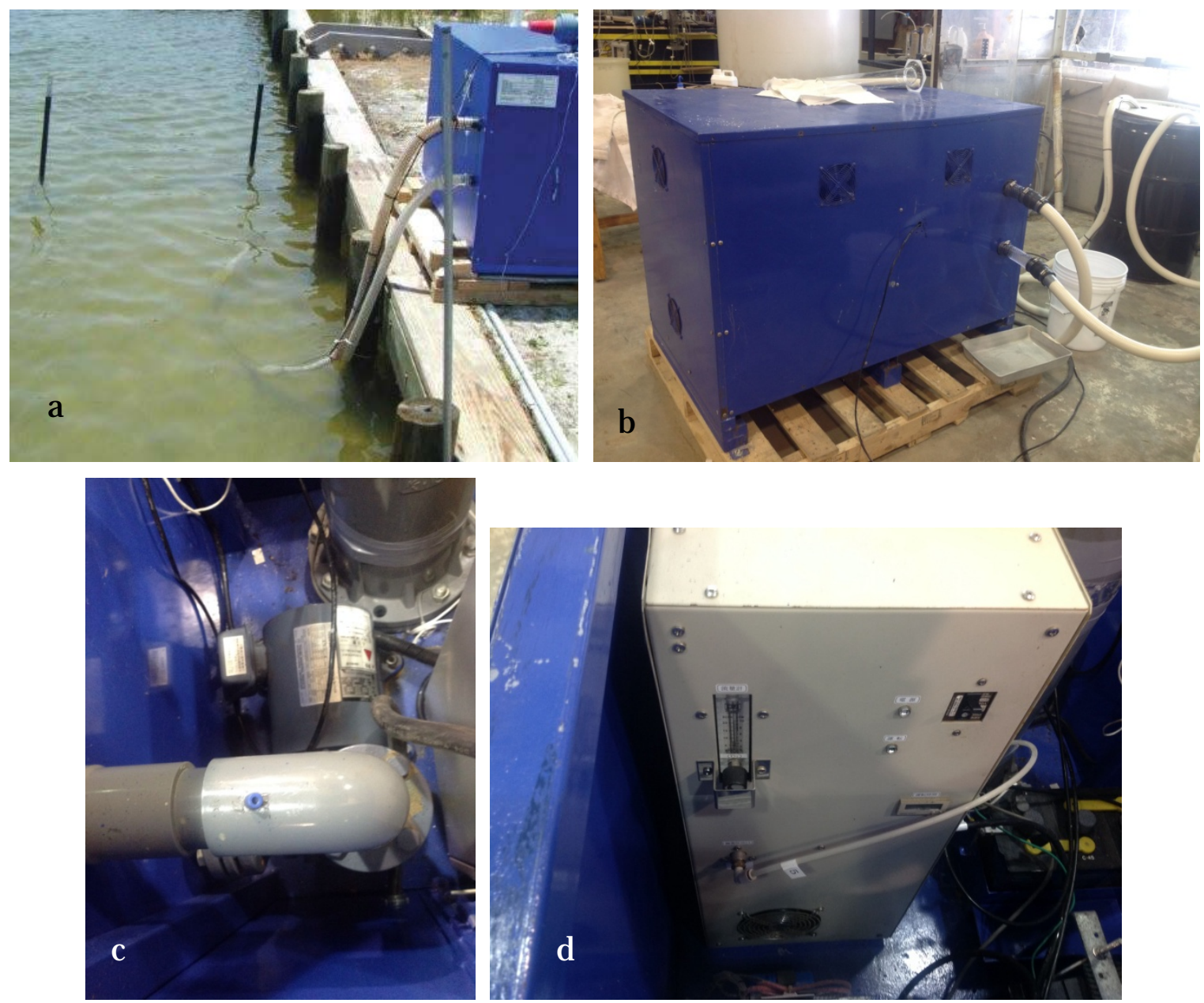

important part of this metal's reactive capabilities (Gerischer and Heller 1991, Howe and Gratzel 1985, Mascolo et al. 2008, Mezyk et al. 2013, Shephard et al. 1998). Superoxide can be derived from the disassociation of inorganic superoxide salts, such as potassium superoxide $\left(\mathrm{KO}_{2}\right)$ (Poupko and Rosenthal 1973). Superoxide is also produced by a fungus (Stibella aciculosa) as part of its reproductive process, and this has been studied for the treatment of mining contamination (Hansel et al. 2012).

Superoxide is interesting in that it can perform nucleophillic oxidative and reductive reactions (Poupko and Rosenthal 1973 showed reductive reactions with quinines and nitro-substituted hydrocarbons and oxidative reactions with amine groups). This property may expand the possibilities for applying superoxide to various contaminants. In fact, superoxide can allow for reductive reactions to occur in aerated waters, which is a very unique property (Mezyk et al. 2013). 
Superoxide has been described as weakly reactive or even inert. These descriptions are, however, contradicted by numerous studies showing significant transformation and degradation of several types of contaminants. Superoxide is an effective reductant capable of transforming carbon tetrachloride and hexachloroethane (Watts et al. 1999, Teel and Watts 2002). Roberts and Sawyer (1981) reported rapid (with rate constants on the order of seconds) transformation of several chlorinated solvents and pesticides in reaction with superoxide, although the studies were conducted in aprotic media. Aprotic media minimizes reactions with water, which can consume the superoxide molecule. There is also evidence that Fenton's generated superoxide radicals can also attack nitroaromatic explosives (Rodgers and Bunce 2001); a theory further supported by studies demonstrating superoxide reduction of nitro-substituted compounds (Bielski et al. 1980, Poupko and Rosenthal 1973). Similarly, Schmelling et al. (1996) found TNT degradation in $\mathrm{a} \mathrm{TiO}_{2}$ reaction tuned to generate superoxide anions. Shephard et al. (1998) speculated that superoxide had a critical role in $\mathrm{TiO}_{2}$-mediated degradation of microcystin, a toxin produced by cyanobacteria. Mascolo et al. (2008) found ultraviolet (UV)-activated $\mathrm{TiO}_{2}$ reactions degraded compounds like methyl-tert-butyl-ether (MTBE), benzene, alkyl-benzenes, and alkyl-naphthalenes, although reactions were not as effective as UV-activated hydrogen peroxide due to fouling issues with the $\mathrm{TiO}_{2}$ catalyst. Still, the better removal of hexadecane by the $\mathrm{UV} / \mathrm{TiO}_{2}$ system was directly attributed to superoxides. Chen et al. (2012) found effective degradation of dimethyl phthalate by superoxide that was created by iron reactions with microwave stimulation. J oo et al. (2004) demonstrated effective destruction of the herbicide, molinate, by superoxide radicals generated from zero valent iron corrosion.

Superoxide is apparently less toxic to microorganisms than other radicals. Watts et al. (2003) found it was less toxic to Escherichia coli than hydrogen peroxide and hydroxyl radicals, which could be useful in groundwater remediation applications where it is desirable to promote biodegradation along with abiotic transformations. Another interesting property of superoxide is that it seems to promote contaminant desorption, which can be useful in treating soils, sediments, and groundwater aquifers (Corbin et al. 2007).

\section{Other potential reactions from KRIA operation}

The KRIA is primarily designed to produce the superoxide radical. However, the reactor also promotes other reactions that might be 
significant in addressing environmental issues. First, the reactor is a strong oxygenator (see results below). The high oxygen content provided by the operation could, by itself, promote high rates of aerobic degradation. The second key mechanism is that the superoxide is injected into the discharge as microbubbles. Microbubbles have been explored for their reactivity with contaminants (Agarwal et al. 2011, Li et al. 2009) and disinfections (Agarwal et al. 2011), as well as for their ability to promote contaminant desorption (Ueda et al. 2013). A third mechanism is cavitation (Zhang and Hua 2000), which could occur at the impeller of the recirculation system (microbubble reactions are also a form of cavitation). Because our controls (see methods) include the recirculation pump, any affects from this are addressed. For the purposes of this work, we will assume that the bulk of any other reactions are due primarily to superoxide.

\section{Results of Studies Provided by Premier Materials}

Premier Materials provided reports on six applications of the KRIA system. One report was on an application at Grand Lake, $\mathrm{OH}$, from 28 August to 17 October 2012 - a period of about six weeks. During this time, a number of water quality parameters were measured. Substantial increases were found in dissolved oxygen (DO) measurements, increasing from an average of 4.97 to $9.38 \mathrm{mg} / \mathrm{L}$. Increases in DO were also found in sediment samples. The range of Oxidation-Reduction Potential (ORP) measurements increased from an initial range of 99.3 to $184.1 \mathrm{mV}$ to 189.9 to $201.0 \mathrm{mV}$. Ammonia levels dropped from as high as $0.56 \mathrm{mg} / \mathrm{L}$ to as low as non-detect, and phosphate levels also dropped. Algae concentrations dropped, except for one cyanobacteria species, which actually increased. However, a report provided by Mad Scientists \&Associates (2012) indicated that although many water quality parameters improved during the KRIA treatment period, similar changes also occurred in an untreated control area, and the differences were not statistically significant.

A second application described was at a fish (globefish) hatchery in J apan. The hatchery had maintained high DO concentrations to support globefish through the use of liquid oxygen and antibiotics to control infections. A 10-week study was conducted on a portion of the hatchery using the KRIA ionizer instead. The ionizer proved to be an outstanding water oxygenator, and it operated at about a tenth of the cost of the liquid oxygen system. In addition, fish thrived in the system without the antibiotics. In the KRIAtreated water, the fish were a larger average adult weight and a 
substantially higher yield (90\% vs. $40 \%$ ), as compared to the liquid oxygen/ antibiotic system.

A third report discusses an application at Orange Beach, AL, in a harbor area that was impacted by the Deepwater Horizon oil spill (Premier Materials 2013). The KRIA water treatment system was installed approximately one year after the spill. The DO levels taken near the reactor increased from 5.0 to over $11.0 \mathrm{mg} / \mathrm{L}$. Visibility within a $1000 \mathrm{ft}$ radius of the reactor reportedly improved, and fish and crabs, which had not been found prior to the KRIA's deployment returned (the wildlife and visibility were confirmed by a local resident, Ms. Margaret Childress Long, a local resident who maintained a daily diary documenting the spill and the KRIA deployment).

A fourth study was described in the text of e-mail from Mr. Mike Mangham of EcoUSA and involves a 2001 study at a pond in the Ueno Zoo in Tokyo, J apan. The study took samples from a zone of influence of the KRIA and outside of the test zone as a control. Table 1 summarizes measurements taken on 31 August 2001. The data showed reductions in organic matter (decreased biological oxygen demand (BOD) and chemical oxygen demand (COD)). Decreases were also found in suspended solids (ss), total nitrogen, and total phosphorus. The $\mathrm{pH}$ had a substantial drop from 8.7 to 6.7. The changes in BOD and COD can be attributed to degradation either due to direct interaction with the superoxide or from stimulated microbial activity. The changes in ss, nitrogen, and phosphorus are more difficult to explain. A portion of the ss reduction may be related to degradation of organic material, but it seems unlikely that such a high percentage (98\%) of suspended material would be from organic material. Similarly, changes in nitrogen and phosphorus are difficult to explain by direct interaction with the KRIA process. This could suggest more complex interactions resulting in the KRIA operation that promotes particle setting, or that the sites had some inherent difference. This issue is further covered in the discussion section. 
Table 1. Data from study conducted at Ueno Zoo, Tokyo, Japan, 31 August 2001.

\begin{tabular}{|l|c|c|}
\hline \multicolumn{1}{|c|}{ Parameter } & Outside of Test Zone & Inside of Zone \\
\hline $\mathrm{pH}$ & 8.9 & 6.7 \\
\hline $\mathrm{BOD}(\mathrm{mg} / \mathrm{L})$ & 8.5 & 2.2 \\
\hline $\mathrm{COD}(\mathrm{mg} / \mathrm{L})$ & 19 & 3.7 \\
\hline $\mathrm{SS}(\mathrm{mg} / \mathrm{L})$ & 100 & 2.0 \\
\hline Total Nitrogen $(\mathrm{mg} / \mathrm{L})$ & 2.6 & 0.38 \\
\hline Total Phosphorus $(\mathrm{mg} / \mathrm{L})$ & 0.26 & 0.025 \\
\hline
\end{tabular}

A fifth study that was described in a series of e-mails from Mr. Mike Mangham was an application on the soils surrounding the Fukushima reactor in J apan. Superoxide-laden water from a KRIA system was applied to soils that were contaminated by cesium, strontium, and other radionuclides. Gamma radiation was reduced after the superoxide treatment, presumably because the radioisotopes were solubilized and rinsed off the soil. The study hypothesized that the superoxide enhanced removal by oxidizing the radioactive species. The enhanced removal by oxidation is in line with studies conducted to remove depleted uranium species from soils. ${ }^{1}$

A last study was conducted on disinfection properties of ECOCLEAN, which is a product developed from the same superoxide-generating process as the KRIA water treatment system. A wastewater with microorganisms was treated with $100 \%, 20 \%$, and $10 \%$ ECOCLEAN concentrations after 10-minute exposures, and the results are given in Table 2. The actual dilution from the ECOCLEAN addition was not recorded.

Table 2. Disinfection using ECOCLEAN solution (counts per $\mathrm{mL}$ ).

\begin{tabular}{|l|c|c|c|}
\hline & Coliform Bacteria & Staphylococcus & Salmonella \\
\hline No treatment & $9.4 \times 10^{6}$ & $2.1 \times 10^{6}$ & $1.2 \times 10^{6}$ \\
\hline $100 \%$ ECOCLEAN & 0 & 7 & 0 \\
\hline $20 \%$ ECOCLEAN & 1 & $1 \times 10^{4}$ & 0 \\
\hline $10 \%$ ECOCLEAN & 2 & $1 \times 10^{4}$ & 0 \\
\hline
\end{tabular}

\footnotetext{
1 Griggs, Chris. 2014. Personal Communication with Victor F. Medina. April 16. U. S. Army Engineer Research and Development Center, Vicksburg, MS
} 
Although the results reported in these studies are promising, there are issues that are commonly found in field studies that can make these results difficult to interpret, making the results somewhat dubious. For example, some of the studies rely on comparisons of before and after KRIA deployment, without factoring in the possibility of temporal changes. For example, although the data from the Grand Lake study were promising, lacustrine chemistry tends to undergo changes over time as a consequence of changes in sunlight intensity, temperature, and mixing in the lake. The subsequent report by Mad Scientists \&Associates (2012) also included a control area, and similar changes occurred in that area. The Ueno Zoo data apparently included a control area (not affected by the KRIA), but it is often difficult for control areas to be completely similar in natural systems. Since the study locations for the Grand Lake and the Orange Beach study were not contained, changes due to influx and outflux also potentially complicate the results. That said, the studies consistently show positive results from the KRIA application, suggesting that the KRIA water system is a promising technology for addressing a wide range of water quality issues.

The purpose of this project was to study and demonstrate the KRIA system in a highly controlled setting, so that any changes found could be directly attributed to the reactor. Using these studies in conjunction with the field studies described above should provide potential users with sufficient background to decide whether the KRIA system is a good fit to address their water quality issues; although in some cases, a laboratory or controlled field test might be useful. 


\section{Approach}

\section{General Experimental Setup}

Two identical, lined, 55-gallon-drum test reactors were prepared. A top was engineered by cutting holes for the reactor inlet/ discharge to limit volatilization while allowing for the KRIA nozzles to be inserted in the water.

\section{Experimental Approach}

The two test reactors were filled with 50 gallons of clean water; next, they were spiked with the constituent of interest to meet the target concentration; then mixed with a large propeller mixer (Figure 2). Table 3 summarizes the constituents tested and their initial concentrations. Both reactors were then sampled in triplicate to establish their initial concentrations. One of the vessels was then treated with the KRIA Ionizer for a treatment time of one hour. After this treatment, a triplicated sample was immediately taken to evaluate the treatment. Following treatment, unreplicated samples were collected at 2, 4, and 8 hours (24 hours for the PCB study) to evaluate degradation by residual superoxide radicals.

Seventy-two hours after the treatment period, the team took one triplicated sample from each of the reactors. The control underwent an identical process to simulate the effect of the KRIA reactor in all ways, except that the valve controlling the superoxide reservoir in the reactor was turned off (Figure 2); consequently, it was mixed by the sump pump mechanism but was not charged with the superoxide. The control was sampled identically, resulting in a total of 24 samples that were collected for this study. In addition, a study was conducted with no contaminants, with the purpose of measuring changes in water quality parameters (temperature, $\mathrm{pH}$, conductivity, ORP) and measuring superoxide concentrations in the two reactors.

After each experiment, the reactors were drained and the solutions prepared for appropriate disposal. The liners were removed and replaced in each drum. The hoses on the KRIA system were also exchanged with fresh hoses to eliminate cross contamination issues. 
Figure 2. Propeller mixer (a) and on/off valve for superoxide reservoir (in "off" position, b).
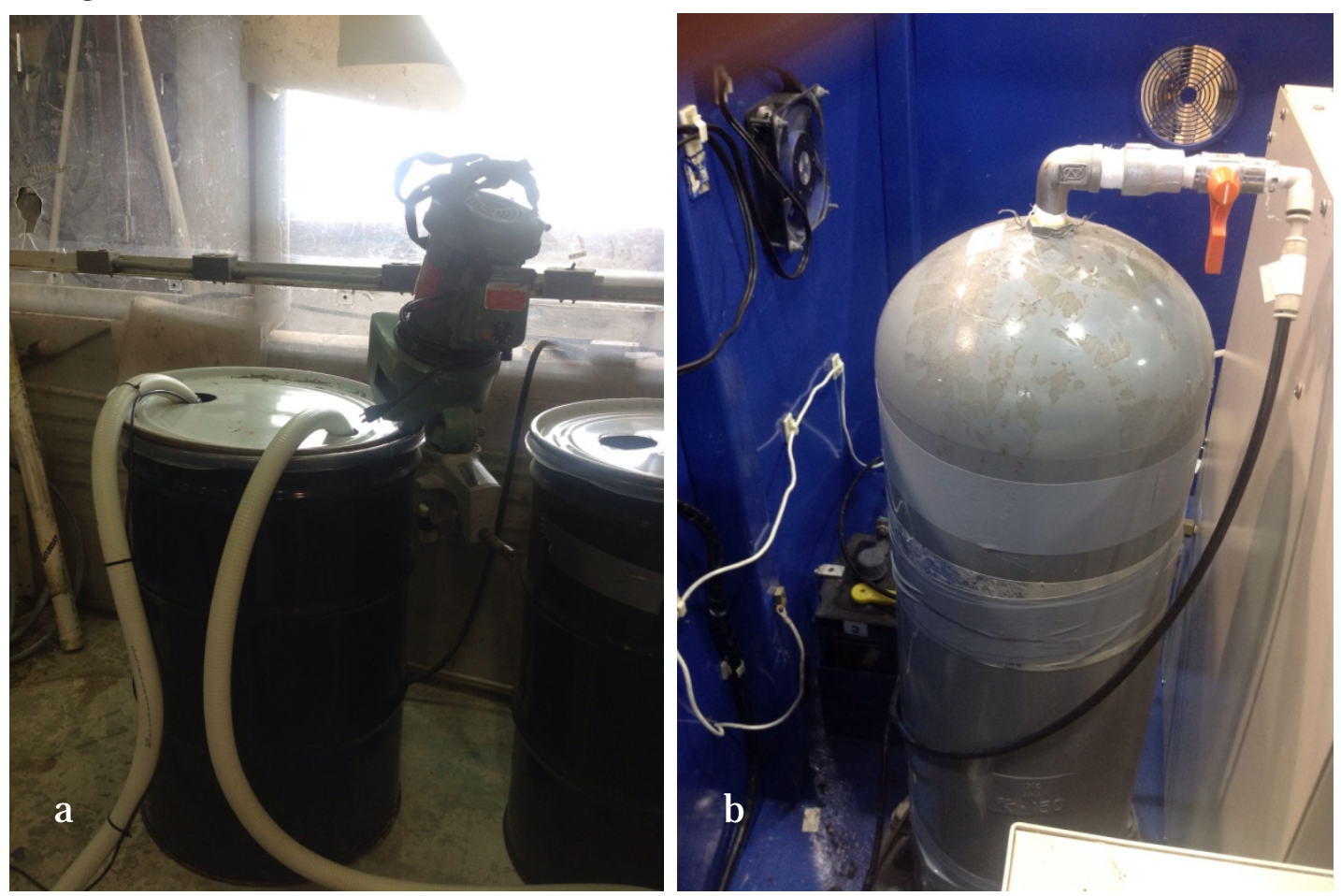

Table 3. Constituents tested and initial target concentrations.

\begin{tabular}{|l|l|l|}
\hline Constituent & Target Concentration & Analytical Method \\
\hline Diesel & $10 \mathrm{mg} / \mathrm{L}$ & EPA 8015 \\
\hline Arochlor 1254 (PCB) & $1 \mathrm{mg} / \mathrm{L}$ & EPA 8082 \\
\hline Ammonium Nitrate & $20 \mathrm{mg} / \mathrm{L}$ & lon chromatography \\
\hline
\end{tabular}

\section{Measurements}

Temperature, $\mathrm{pH}$, conductivity, dissolved oxygen, and oxidation/reduction potential (ORP) were all measured by calibrated meters. Semi-quantitative superoxide concentrations were measured using a superoxide dismutase kit (Figure 3 shows plates and reader used in this measurement). Test constituents were measured using methods outlined in Table 1. 
Figure 3. Some of the analytical instruments used in this project. Assay plate reader (upper left) and 96 well plate used for the superoxide dimutase assay (upper right), which were used to semi-quantitatively measure superoxide concentration, and dionex ion chromatograph used for nitrate and nitrite measurements (a similar system was set up for cation measurements and used for ammonium analysis) (lower left). Water quality meter for $\mathrm{pH}$, conductivity, dissolved oxygen (DO), percent oxygen saturation (DO\%), and oxygen-reduction potential (ORP) (lower right).
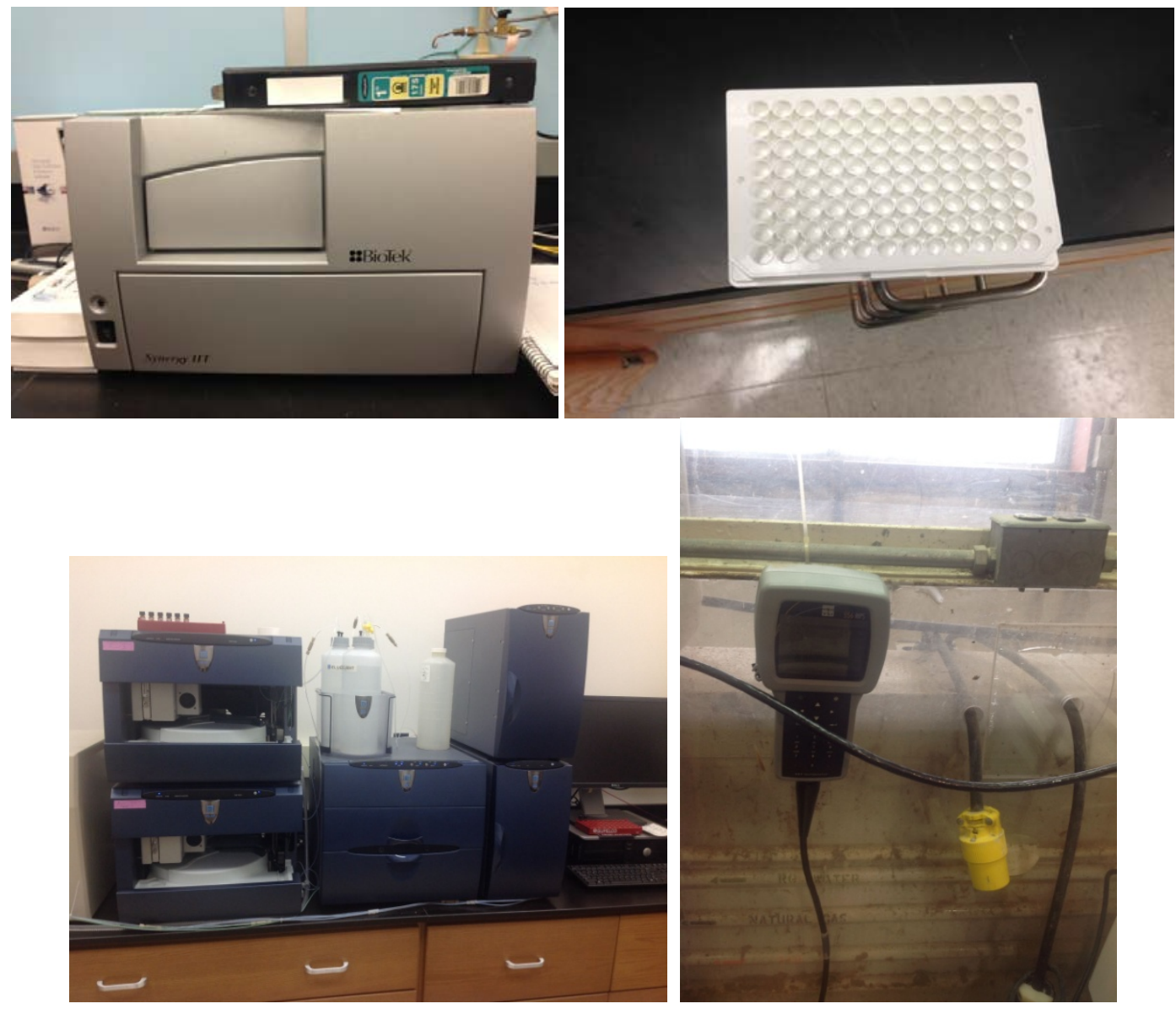


\section{Results}

\section{Effect on General Water Quality Parameters}

Table 4 summarizes water quality parameters measured during a 135minute operation of the KRIA water treatment system, with the superoxide valve open (charging superoxide (SO)) and closed (mixing only, no superoxide). The table also shows measurements taken in the superoxide treated tank 24 hours after the KRIA was shut down. The DO levels in the control remained around 8 to $10 \mathrm{mg} / \mathrm{L}$, giving saturation from 100 to $113 \%$. This contrasted with the superoxide-treated reactor, in which the DO increased from a starting concentration of 8.63, to levels around $30 \mathrm{mg} / \mathrm{L}$ in the SO-treated water, giving a DO\% of over 300 . These results indicate that the KRIA can effectively supersaturate water with oxygen. Furthermore, the sample collected 24 hours after the KRIA was shut down maintained elevated DO and DO\% levels $(28.5 \mathrm{mg} / \mathrm{L}$ and $321 \%$ saturation respectively, indicating that the oxygenation levels remained elevated after the reactor was shut off.

Table 4. Summary of water quality parameter measurements over 135 minutes with KRIA water treatment system operation with superoxide (SO) valve open and closed.

\begin{tabular}{|l|l|r|r|r|r|r|r|r|}
\hline \multirow{3}{*}{ WQ Parameter } & \multicolumn{7}{|c|}{ Mixing Time (minutes) } & \\
\hline \multirow{2}{*}{ temp C } & SO Valve & 0 & 10 & 30 & 60 & 80 & $\begin{array}{l}\text { 24 hr } \\
\text { recovery }\end{array}$ \\
\hline \multirow{2}{*}{ cond mS/cm } & Open & 20.33 & 20.85 & 21.62 & 23.65 & 23.18 & 23.06 & 21.03 \\
\cline { 2 - 9 } & Closed & 20.28 & 20.36 & 20.85 & 21.58 & 22.04 & 22.68 & \\
\hline \multirow{2}{*}{ DO mg/L } & Open & 0.170 & 0.265 & 0.305 & 0.355 & 0.355 & 0.353 & 0.337 \\
\cline { 2 - 10 } & Closed & 0.136 & 0.138 & 0.139 & 0.146 & 0.149 & 0.150 & \\
\hline \multirow{2}{*}{ DO \% } & Open & 8.63 & 30.21 & 30.62 & 30.41 & 30.16 & 29.37 & 28.55 \\
\cline { 2 - 9 } & Closed & 10.34 & 9.13 & 9.09 & 8.91 & 8.76 & 8.56 & \\
\hline \multirow{2}{*}{ pH } & Open & 94.1 & 331.6 & 347.3 & 356.2 & 352.9 & 343.4 & 321.9 \\
\cline { 2 - 9 } & Closed & 113.0 & 101.0 & 102.0 & 100.8 & 100.7 & 100.0 & \\
\hline \multirow{2}{*}{ ORP } & Open & 5.95 & 6.44 & 6.65 & 6.93 & 6.99 & 6.92 & 6.65 \\
\cline { 2 - 9 } & Closed & 4.68 & 5.28 & 5.71 & 6.04 & 5.87 & 6.28 & \\
\hline & Open & -35.3 & -23.0 & -29.3 & -46.3 & -51.7 & -59.6 & -41.3 \\
\cline { 2 - 9 } & Closed & -22.5 & -31.0 & -32.7 & -37.6 & -36.8 & -41.7 & \\
\hline
\end{tabular}

Conductivity is a measure of electrical transmission in water and is related to the concentration of ionic species in the water. Conductivity in the superoxide-exposed water increased from 0.170 to $0.355 \mathrm{mS} / \mathrm{cm}$ at 60 
minutes and remained stable at this level through the 135-minute operation. The control did not show this increase. Since superoxide is an anion, it serves to increase the conductivity of the water. Although high conductivity can indicate water is brackish or salty (for example, sea water has a conductivity of about $5 \mathrm{mS} / \mathrm{cm}$ ), conductivity by itself does not indicate if a water source is better than another. For example, natural freshwater streams can vary from 0.100 to $2.000 \mathrm{mS} / \mathrm{cm}$, while potable water sources in the U.S. vary from 0.030 to $2 \mathrm{mS} / \mathrm{cm}$, and tap water can vary from 0.050 to $0.800 \mathrm{mS} / \mathrm{cm}$ (CWT 2004). The ranges found in this study (from 0.136 to $0.355 \mathrm{mS} / \mathrm{cm}$ ) are within ranges of good quality water. Conductivity was also measured 24 hours after the KRIA was shut off, and it still was above $0.300 \mathrm{mS} / \mathrm{cm}$. This suggests that the superoxide radicals were still present after shutdown, which indicates strong persistence of these radicals. The conductivity results contrast with those found in the Grand Lake studies, where reductions were found in conductivity levels. This contradiction shows the complication of field studies, and how they can sometimes lead to confusing results. It is likely that the decrease was due to more complex reactions, or possibly due to changes in the lake independent of the KRIA operation.

Temperature was found to increase about equally (on the order of $2.7^{\circ} \mathrm{C}$ ) in both the KRIA and control reactors, presumably due to the mixing action of the recirculating pump. The $\mathrm{pH}$ increased in both the control and SOtreated reactors, with the increase being somewhat higher in the control. The ORP decreased in both the control and the SO-treated reactors, with a more prominent decrease in the SO-treated reactor (from -35.3 to -59.6). This suggests that the tendency of SO is to act as a reductant. However, with the increase of oxygen in the system, the system is also becoming more oxidizing. So, it seems like the SO environment creates an interested environment, where both oxidation and reduction can occur.

\section{Production of Superoxide}

In this study, the KRIA was operated for four hours in the treatment reactor (superoxide). Similarly, the reactor was operated for four hours in the control, but with the valve to the superoxide tank shut off. Samples were taken hourly and applied to a standard 96 well plate that was set up using a superoxide dimutase enzyme-linked immunosorbent assay (ELISA). The plates were read by a multiwell plate reader (Figure 3). 
The team found that the plates reacted with both the superoxide and the control, giving positive values for superoxide dimutase activity (Figure 4). One possibility is that even with the valve off, some of the superoxide still made its way into the control. These seem unlikely, however, since ball valves, such as the one used, generally perform effectively. More likely cavitation at the injection nozzle resulted in the formation of radical species like super oxide (Suhr et al. 1991). The values for the superoxide reactor were three to five times higher than the control. This study confirms that the KRIA produces superoxide. However, this study was semi-quantitative. Without a standard, we can only say that more superoxide was produced by the KRIA reactor, but the team cannot give a concentration of the superoxide radical.

Figure 4. Superoxide activity as measured using SOD assay.

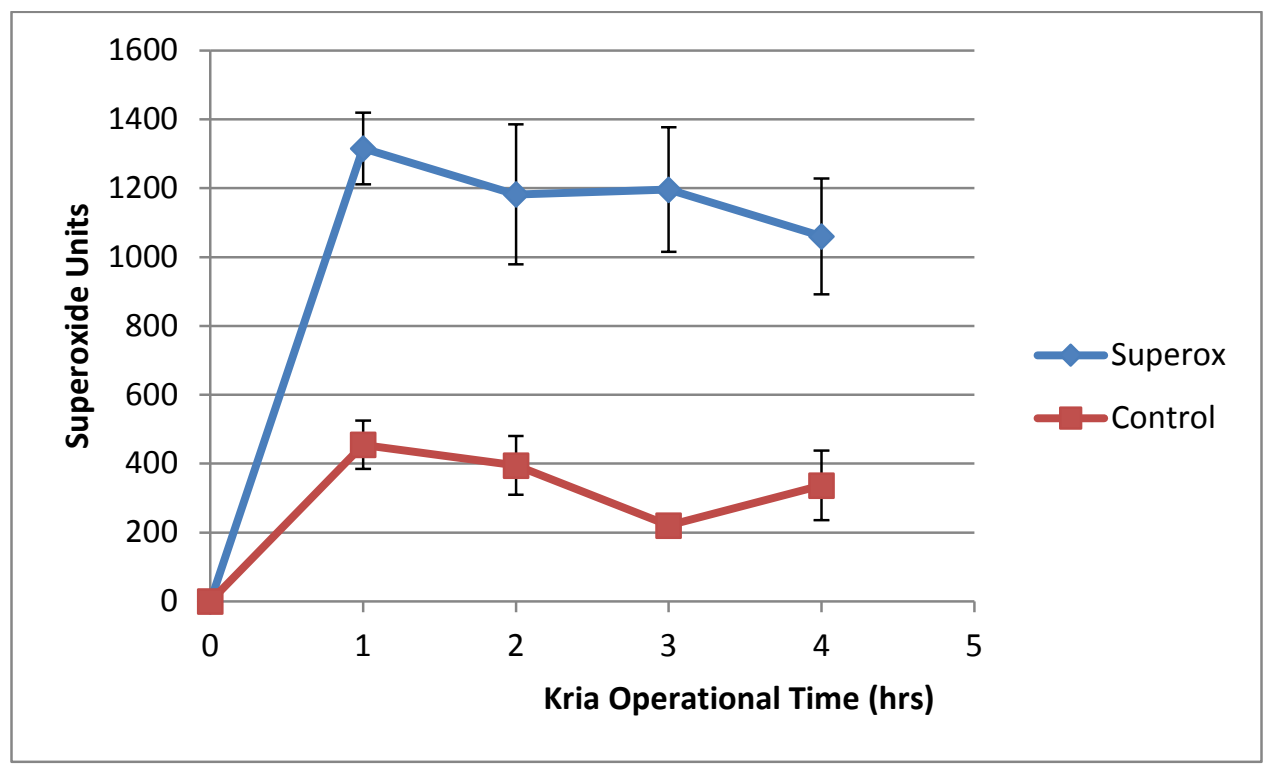

\section{Treatment of Diesel}

Figure 5 summarizes the results of the diesel treatment experiment. The time zero (T0) samples of both were very close, 5.44 and $5.08 \mathrm{mg} / \mathrm{L}$. The authors hypothesize that some of the diesel preferentially floated to the surface, which resulted in a lower concentration in the middle of the tank where the sample was taken. After the reactor was run, the measured concentrations (T1) were actually higher, $7.72 \mathrm{mg} / \mathrm{L}$ for the KRIA superoxide, and $16.4 \mathrm{mg} / \mathrm{L}$ for the control. The authors think that these higher concentrations resulted from the mixing of the reactor, mixing in the diesel that had been floating, and yielding a higher concentration. However, the superoxide reactor (Drum 1) concentration was about half that of the control. 
Figure 5. PCB concentrations in superoxide (SO) and control reactors. TO is after spiking, T1 is 1 hour after KRIA operation, T2 is 2 hours, T3 is 4 hours, T4 is 24 hours, and T5 is

72 hours. Error bars represent standard deviation among triplicated samples.

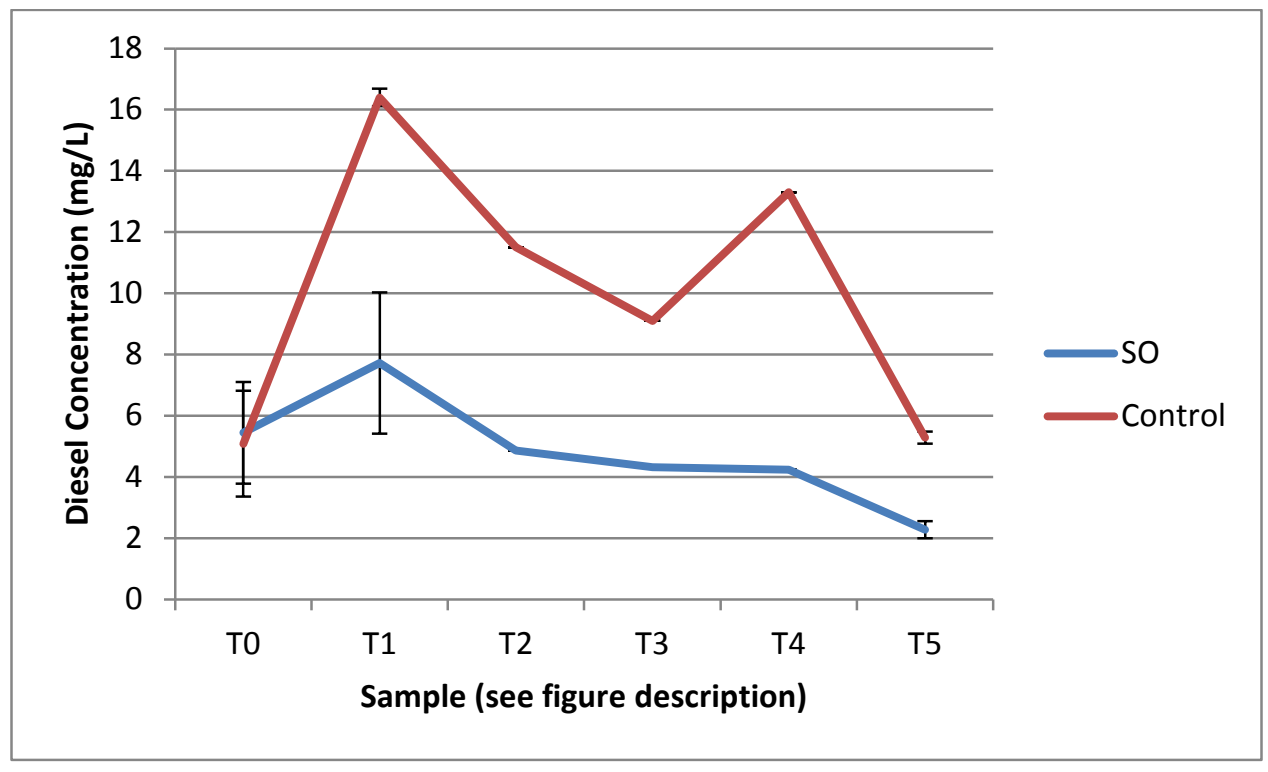

The 2-, 4-, and 8-hour samples (T2, 3, and 4) for the superoxide had a slight but steady decrease compared to the T0 sample, lowering the concentration to $4.3 \mathrm{mg} / \mathrm{L}$, while the concentrations for the control during these times were around 10, which was about twice the T0 sample. The T5 sample for the superoxide reactor was 2.27, and was 5.28 for the control. Therefore, the superoxide reactor had 58\% removal of the diesel after 72 hours, while the control, which had identical mixing but was not charged with superoxide, had no removal.

The results seem to show immediate treatment, as we see significant removal after 2 hours. However, substantial removal occurred between the 8- and 72-hour samples, suggesting that the superoxide anion continues in its activity over time. In summary, the results show a definite decrease in diesel concentrations in the KRIA superoxide reactor, while none in the control. By experimenting with the actual treatment time, mixing, and other parameters, treatment could be potentially improved.

\section{Treatment of PCBs (Arochlor 1254)}

Figure 6 summarizes the results of the PCB study. When comparing this to the diesel results, the reader should be aware that the concentration units are different (ug/ $\mathrm{L}$ for the PCB test compared to $\mathrm{mg} / \mathrm{L}$ for the diesel test). The team used a single Arochlor, 1254, and measurements focused only on that Arochlor. 
Figure 6. PCB concentrations in superoxide (SO) and control reactors. TO is after spiking, T1 is one hour after KRIA operation, T2 is 2 hours, T3 is 4 hours, T4 is 24 hours, and T5 is

72 hours. Error bars represent standard deviation among triplicated samples.

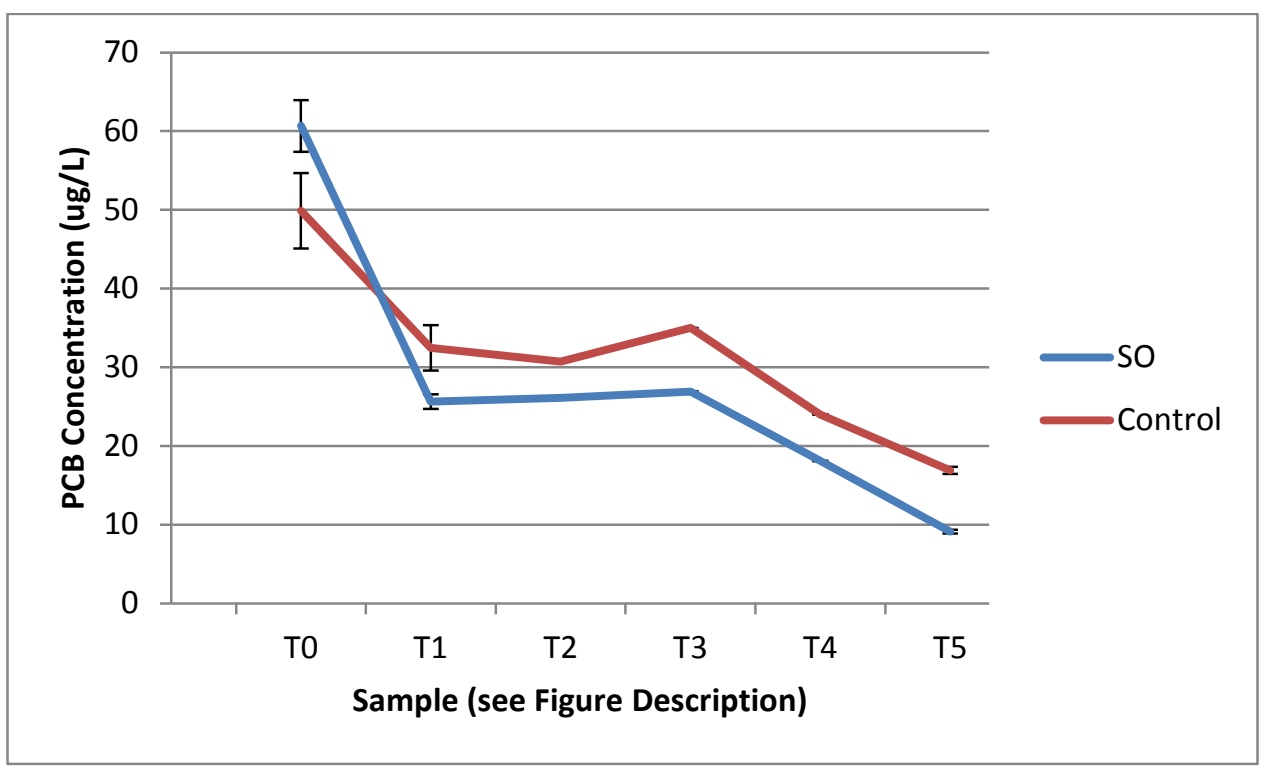

In analyzing these results, it is useful to start with PCB T0 data. Although the team tried to spike both reactors identically, the PCB was a bit higher in concentration in the SO-treated reactor as compared to the control.

In the diesel test, there was no contaminant removal in the control, so all the removal in the KRIA-treated reactor could be accounted for by the KRIA action (superoxide, microbubbles, etc). In the PCB test, there is removal in the control. Consequently, the authors cannot claim that all the removal was from the KRIA. PCBs have low solubility and tend to adsorb, so it is likely that the losses in the control reactor, which were up to $65 \%$ at the 72 -hour mark (T5), were due to adsorption on the drum liner and even possibly in the tubing of the KRIA. Another mechanism of removal in the control could have been reactions associated with cavitation at the pump impellor (Zhang and Hua 2000), which was part of the recirculation mechanism.

However, the percentage removed in the KRIA-treated drum were higher in each measurement, and the amount removed at 72 hours (T5) was 85\%; $20 \%$ higher than in the control. Samples at T0, T1, and T5 were tripilicated, allowing the team to calculate deviations. The deviations were small compared to the average measurements, indicating that variability was low. The removals by the KRIA were statistically significant compared to the control. 
Samples for chloride analysis were taken at 72 hours. If PCBs completely degrade, they should release chloride. The team's analyses did not find a measurable increase in chloride at 72 hours $(16.04 \mathrm{mg} / \mathrm{L}$ in the control vs. 15.63 in the SO treated). However, the results may have been masked by the background chloride, which was on the order of 15 - $16 \mathrm{mg} / \mathrm{L}$. PCB levels were on the order of 50 to $60 \mathrm{ug} / \mathrm{L}$ (or 0.05 to $0.06 \mathrm{mg} / \mathrm{L}$ ) and any chloride released would have been a fraction of these numbers. Consequently, even if chloride evolution had occurred, it likely would have been too small to detect.

These results are not as elegant as the diesel test, and certainly more testing could be conducted to better refine the results. However, for a preliminary test where so many things can go wrong, the results are very good. They certainly show substantial differences between the KRIA and the control.

\section{Treatment of Nutrients as Nitrogen Forms}

The nutrient treatment test did not indicate any treatment trends. In the control reactor, nitrate concentrations ranged from 27.80 to $28.20 \mathrm{mg} / \mathrm{L}$, compared to from 27.84 to $28.66 \mathrm{mg} / \mathrm{L}$ for the superoxide reactor. Nitrite in the control ranged from 3.81 to $3.86 \mathrm{mg} / \mathrm{L}$, and ranged from 3.77 to $3.92 \mathrm{mg} / \mathrm{L}$ in the superoxide reactor. Ammonia concentrations in the control ranged from 10.44 to $11.18 \mathrm{mg} / \mathrm{L}$ and from 11.32 to $11.48 \mathrm{mg} / \mathrm{L}$ in the superoxide treated. There did not appear to be any clear pattern in these various measurements. Thus, it did not appear that superoxide directly affected concentrations of these nitrogen forms in water. 


\section{Discussion}

\section{Optimization}

The experiments conducted in this study can best be categorized as preliminary feasibility in nature. There are certainly several means to optimize and improve performance. One means might be to experiment with water quality parameters that might affect superoxide reactions, such as $\mathrm{pH}$, temperature, conductivity, and the presence of key ionic species. High $\mathrm{pH}$, for example, promotes more superoxide formation in Fenton's chemistry reactions and the presence of $\mathrm{Fe}^{2+}$ and $\mathrm{Cu}^{2+}$ can also increase superoxide production and stability, although too high a concentration can actually suppress a superoxide concentration (Qiao et al. 2001). Another parameter that could be varied would be the superoxide charging time, which could easily be increased. Alternatively, sequential charging could be investigated.

\section{Potential Applications}

Based on the results of this study, several interesting applications for the KRIA can be envisioned. The supersaturation of oxygen achieved makes the KRIA a very promising reactor for numerous applications. For small lakes, ponds, and wetlands, the KRIA could be useful in providing mixing and oxygenation to combat eutrophication and algal blooms. Mixing can be an effective means for controlling algae in ponds and reservoirs, particularly in highly stratified water (Chipofya and Matapa 2003, Cong et al. 2011, Daldorph 1998), and the action taken by the KRIA provides a strong mixing component. The oxygenation is also valuable in preventing anoxic conditions associated with eutrophication (Hammer 1986). The KRIA might find application in conjunction with sewage outfalls to address depressions in DO associated with that activity (Hammer 1986). Similarly, the oxygenation aspect of the KRIA is attractive for wastewater treatment, and is particularly suitable for applications in simple lagoons. Lagoons are easy to construct and utilize for forward operating base wastewater sanitation (ECAT 2010, Noblis 2010), disaster relief, and humanitarian missions. However, if overwhelmed, these lagoons can become septic, a situation that reduces treatment effectiveness and generates fetid odors. The KRIA could provide very effective oxygenation for these applications to promote biological activity, and could promote 
mixing as well. In addition, the superoxide could assist in directly degrading organic compounds, further improving treatment efficiency.

The strong results found in degrading diesel suggest that the KRIA may also be very valuable in treating water contaminated with petroleum hydrocarbons without the need of additional extensive testing. These could include low level contaminated water from oil spills, contaminated water from groundwater remediation applications, and water associated with the production or refining of petrochemicals. One very interesting application that should be attractive for testing is fluids associated with hydrofracturing (fracking), although these fluids contain a much broader range of potential contaminants that may require some additional testing to address (Medina 2014).

The $\mathrm{PCB}$ results were promising, but with removal in the control and the lack of measurable chloride data, the results were still somewhat inconclusive. However, the literature also supports the potential for effective treatment as well (Fang et al. 2013a, 2013b, 2013c). A reasonable approach might be to recommend a field treatability study as a first step in such a project. PCBs could be found in aqueous solutions in rivers and lakes with highly contaminated sediments, from groundwater pump and treat systems, or from soil and sediment remediation projects in which PCBs are leached or chemically removed from the granular materials.

The KRIA could also be adapted for injection into granular media for PCB and hydrocarbon remediation (and other applicable contaminants), which would open up opportunities for the direct treatment of contaminated soils (by leaching applications), sediments, and groundwater. Granular media applications may benefit from microbubble interactions and superoxide properties, which increase contaminant availability (Corbin et al. 2007, Ueno 2013), promoting more thorough remediation of the sediment/ soil/ aquifer material. In fact, the KRIA has received an acceptance letter from the Florida Department of Environmental Protection that includes an authorization to commence subsurface injection into soil and groundwater (Ruscito and Lockenbach 2013).

The results from this study did not directly support the use of the KRIA for nitrogen nutrients. However, the study only evaluated the direct interaction of the superoxide with dissolved nitrate and ammonia. The application at Grand Lake appeared to affect both nitrogen and phosphorus nutrients. Similarly, the application at the Ueno Zoo Lake saw substantial reductions 
of nitrogen and phosphorus, along with 98\% removal of suspended solids. In addition, the Orange Beach study had reports of substantial improvements in water clarity. One explanation could be that the controls of each of these studies had differences that resulted in differences in solids, water clarity, and nutrients (due to temporal differences at Grand Lake and Orange Beach and spatial differences at Ueno). However, it is a point of interest that all these studies had the same pattern of improved clarity/ lower suspended solids and nutrients. This suggests that the KRIA may promote settling of ss, which would, in turn, reduce associated nutrient concentrations. The authors recommend that solids, turbidity, and nutrients be monitored in future field applications, which may continue to support this application. If so, another laboratory study could be designed to account for additional interactions that may affect nutrients.

\section{Other Factors That Might Affect Performance}

The simplicity of the reactor scheme used in this experiment may not factor in other important interactions that might affect performance in the field. Competing organic materials react with the superoxide, resulting in lower contaminant removal rates and treatment percentages. Superoxide adsorption and reactions with soils and sediments may also lower performance.

Conversely, there are factors that might improve performance as well. As mentioned above, the KRIA is a powerful oxygenator. This could stimulate vigorous biological activity. A synergistic effect could result from partial degradation of contaminants by direct interaction with the superoxide radical coupled with subsequent biodegradation by stimulated bacteria.

Another effect not evaluated in these could be further radical generation. Reactions with dissolved ionic material or with soils and sediments or magnetite could spur the formation of other radicals, including the very powerful hydroxyl radical (Fang et al. 2013a, 2013b, 2013c, Kim et al. 2005, Miller and Valentine 1995). Since the team's reactors were aqueous only, there was no mechanism to promote the formation of hydroxyl and other radicals. It has been speculated that the superoxide and hydroxyl radical could work synergistically to promote degradation of recalcitrant compounds like chlorinated compounds. Superoxide generated from fungi can reportedly oxidize metals - particularly manganese - to increase their reactivity with environmental contaminants (Hanson et al. 2012). These secondary reactions could significantly improve performance and expand the range of contaminants that can be treated. 


\section{Conclusions and Recommendations}

\section{Conclusions}

The following conclusions were drawn from this study:

- The superoxide treatment from the KRIA reactor was very effective for treating diesel in aqueous solution, with 58\% removal in the treatment reactor compared to no removal in the control. Better treatment could be potentially obtained by optimizing the treatment process. This suggests that the KRIA could be useful for treating dilutely contaminated water from oil spills, dredging, oil production, etc.

- The PCB results were not as clear as the diesel study, as removal also occurred in the control, and the chloride results were inconclusive. However, there was more removal in the superoxide-treated reactor, and the greater removal was statistically significant. These results, coupled with results found in the literature, support the idea of further studies for applications on PCB treatment in contaminated water, groundwater, soils, and sediments.

- The treatment on the nitrate-ammonia water system did not show any direct interactions with the superoxide on these species (as well as nitrite). This contrasts with results found in field studies with the KRIA. However, the laboratory experiments do not simulate more complex interactions that may occur in the field that could affect nutrient concentrations. A review of the field data suggests that nutrient removal may be linked to removal of suspended solids by a mechanism that is not currently identifiable.

\section{Recommendations}

The KRIA water treatment system and its associated treatment with the superoxide radical have many potential uses. The literature on superoxide indicates that it can be effective for a wide range of contaminants and that it can work both oxidatively and reductively. The following recommendations focus particularly on studies that may yield additional funding or that can greatly expand the efficacy of the method:

- Testing should be conducted on a wider range of contaminants. 
- Studies should be undertaken on interactions to produce other radicals, particularly the hydroxyl radical, which could greatly increase the reactivity of the radical species, and expand the uses of the reactor.

- Studies should be carried out to evaluate the application of the KRIA or system similar to the KRIA to granular media, like groundwater aquifers, soils, or contaminated sediments.

- An evaluation should be conducted of the KRIA water system for domestic sewage, with potential application for wastewater treatment in lagoons that would be useful for forward operating bases, disaster relief applications, or even for establishing sanitation in third world countries.

- The KRIA should be tested on solutions associated with fracking and on water bodies affected by fracking operations to assess its utility for these solutions. 


\section{References}

Agarwal, A., W. J . Ng, and Y. Liu. 2011. Principle and applications of microbubble and nanobubble technology for water treatment. Chemosphere 84:1175-1180.

Bielski, B. H., G. G. Shiue, and S. Bajuk. 1980. Reduction of nitro blue tetrazolium by CO2- and O2- radicals. J ournal of Physical Chemistry 84:830-833.

Chen, Y., Z. Ai, and L. Zhang. 2012. Enhanced decomposition of dimethyl phthalate via molecular oxygen activated by $\mathrm{FeO}: \mathrm{Fe}_{2} \mathrm{O}_{3} / \mathrm{AC}$ under microwave irradiation. J ournal of Hazardous Materials 235- 236(0): 92-100.

Chipofya, V. H., and E. J . Matapa. 2003. Destratification of an impounding reservoir using compressed air - cose of Mudi reservoir, Blantyre Malawi. Physics and Chemistry of the Earth 28:1161-1164.

Clean Water Team (CWT). 2004. Electrical Conductivity/ Salinity Fact Sheet. FS-3.1.3.0(EC). In: The Clean Water Team Guidance Compendium for Watershed Monitoring and Assessment, Version 2.0. Division or Water Quality. California State Water Resources Control Board (SWRCB), Sacramento, CA. Available On-line: http://r.search.yahoo.com/_ylt=A0LEV0.e90JTKB0Ajy5XNyoA;_ylu=X3oDMTEyb245a25sBHNIYwNzcg Rwb3MDMTAEY29sbwNiZjEEdnRPZANVSUMXXZE

Cong, H., T. Huang, and B. Chai. 2011. Research on applying a water-lifting aerator to inhibit the growth of algae in a source-water reservoir. International J ournal of Environment and Pollution 45:166-175.

Connelly, N. G., T. Damhus, R. M. Hartshorn, A. T. Hutton. 2005. Nonmenclature of inorganic chemistry. IUPAC Recommendations 2005. RSC Publishing.

Corbin, J . F., A. L. Teel, R. M. Allen-King, and R. J . Watts. 2007. Reactive oxygen species responsible for the enhanced desorption of dodecane in modified Fenton's systems. Water Environmental Research 79:37.

Daldorph, P. W. G. 1998. Management and treatment of algae in lowland reservoirs in Eastern England. Proceedings of the 1997 First IAWQ-IWSA J oint Specialist Conference on Reservoir Management and Water Supply - An Integrated System 37:57-63.

Engineer Collection and Analysis Team (ECAT). 2010. Operation Enduring Freedom J oint Engineer Operations. August 2010. Initial Impressions Report.

Fang, G., D. D. Dionysiou, S. Al-Abed, and D. Zhou. 2013a. Superoxide radical driving the activation of persulfate by magnetite nanoparticles: Implications for the degradation of PCBs. Applied Catalysis B: Environmental 129: 325-332.

Fang, G., D. Zhou, and D. D. Dionysiou. 2013b. Superoxide mediated production of hydroxyl radicals by magnetite nanoparticles: Demonstration in the degradation of 2-chlorobiphenyl. J ournal of Hazardous Materials 250-251: 68-75. 
Fang, G., D. Zhou, and D. D. Dionysiou. 2013c. Superoxide mediated production of hydroxyl radicals by magnetite nanoparticles: Demonstration in the degradation of 2-chlorobiphenyl. J ournal of Hazardous Materials 250- 251(0): 68-75.

Gerischer, H., and A. Heller. 1991. The role of oxygen in photooxidation of organic molecules on semiconductor plates. J ournal of Physical Chemistry 95:52615267.

Hammer, M. J . 1986. Water and Wastewater Technology. 2nd Edition. NewYork, NY: Wiley.

Hanse1, C. M., C. A. Zeiner, C. M. Santelli, and S. M. Webb. 2012. Mn(II) oxidation by ascomycete fungus linked to superoxide production during asexual reproduction. Proceedings of the National Academy of Sciences 109: 12621-126625.

Howe, R. F., and M. Gratzel. 1985. EPR observation of trapped electrons in $\mathrm{TiO}_{2}$. J ournal of Physical Chemistry 89:4495-4499.

J oo, S. H., A. J . Feitz, T. D. Waite. Oxidative degradation of the carbothioate herbicide, molinate, using nanoscale zero-valent iron. Environ. Sci. Technol. 38 (2004) 2242- 2247.

Li, P., M. Takahasi, and K. Chiba. 2009. Degradation of phenol by collapse of microbubbles. Chemosphere 75:1371-1375.

Katsoyiannis, I. A., T. Ruettimann, and S. J . Hug. 2008. pH dependence of Fenton reagent generation and As(III) oxidation and removal by corrosion of zero valent iron in aerated water. Environmental Science \& Technology 42:7424-7430.

Kim, S-S, J-H. Kim, and S-J Han. 2005. Application of the electrokinetic-Fenton process for the remediation of kaolinite contaminated with phenanthrene. J ournal of Hazardous Materials B118:121-131.

Kunio, F., S. Goro, and N. Takeshi. 1999. Method for water quality improvement of rivers, lakes, and ponds, and its device. Certificate of Patent. J apan Patent Office. Patent Number 3280643. Translated to English.

Mad Scientist \&Associates, LLC. 2012. Performance Assessment Report: Kria Ionizer Water Purification System. Grand Lake St. Marys, Ohio. Westerville, OH.

Mascolo, G., R. Ciannarella, L. Balest, and A. Lopez. 2008. Effectiveness of UV-based advanced oxidation processes for the remediation of hydrocarbon pollution in the groundwater: A laboratory investigation. J ournal of Hazardous Materials 152:1138-1145.

Medina, V. F. 2014. Evaluation of hydraulic fracturing (fracking) for potential impact for potential impact on waterways managed by the Army Corps of Engineers. ERDC/TN DOTS-15-1. Vicksburg, MS: U.S. Army Engineer Research and Development Center. 
Mezyk, S. P., K. A. Rickman, C. M. Hirsch, M. K. Dail, J . Scheeler, and T. Foust. 2013. Advanced Oxidation and Reduction Process Radical Generation in the Laboratory and on a Large Scale: An Overview. In Monitoring water quality: Pollution assessment, analysis, and remediation, ed. S. Ahuja, 227-248. Amsterdam, Netherlands: Elsevier.

Miller, C. M., and R. L. Valentine 1995. Hydrogen peroxide decomposition and quinoline degradation in the presence of aquifer material. Water Research 29:2353-2359.

Noblis. 2010. Sustainable Forward Operating Bases. Report for the Strategic Environmental Research and Development Program. Falls Church, VA: Noblis, Inc.

Noubactep, C., and A. Schoner. 2009. Fe0-based alloys for environmental remediation: Thinking outside the box. J ournal of Hazardous Materials 165:1210-1214.

Poupko, R., and I. Rosenthal. 1973. Electron transfer interactions between superoxide and organic compounds. J ournal of Physical Chemistry 77:1722-1724.

Premier Materials. 2013. Case Study: Kria Ionizer cleans Deep Horizon Oil Spill. Minneapolis, MN: Premier Materials

Ruscito, R., and R. S. Lockenbach. 2013. KRIA - EcoUSA Industrial Water Purifier. Tallahassee, FL: Florida Department of Environmental Protection.

Qiao, X., S. Chen, L. Tan, H. Zheng, Y. Ding, and Z. Ping. 2001. Investigation of formation of superoxide radical in DMSO by ESR: Part 1. Influence of $\mathrm{Fe}^{2+}$ and $\mathrm{Cu}^{2+}$. Magnetic Resonance in Chemistry 39:207-211.

Roberts, J . L., and D. T. Sawyer. 1981. Facile degradation by superoxide ion of carbon tetrachloride, chloroform, methylene chloride, and p,p'-DDT in aprotic media. J ournal of the American Chemical Society 103:712-714.

Rodgers, J . D., and N. J . Bunce. 2001. Treatment methods for the remediation of nitroaromatic explosives. Water Research 35:2101-2111.

Schmelling, D. C., K. A. Gray, and P. V. Kamat. 1996. Role of reduction in the photocatalytic degradation of TNT. Environmental Science \& Technology 30:2547- 2555.

Shephard, G. S., S. Stockenstrom, D. DeVilliers, W. J . Engelbrecht, E. W. Sydenham, and G. F. S. Wessels. 1998. Photocatalytic degradation of cyanobacterial microcystin toxins in water. Toxicon. 36:1895-1901.

Suhr, D., F. Brümmer, and D. Hülser. 1991. Cavitation generated free radicals during shock wave exposure: Investigations with cell-free solutions and suspended cells. Ultrasound in Medicine and Biology 17(18):761-768.

Teel, A. L. and R. J . Watts. 2002. Degradation of carbon tetrachloride by modified Fenton's reagent. J ournal of Hazardous Materials 94: 179-189.

Ueda, Y., Y. Tokuda, F. Shigeto, N. Nihei, and T. Oka. 2013. Removal of radioactive Cs from gravel conglomerate using water containing air bubbles. Water Science and Technology 
Watts, R. J., B. C. Bottenberg, M. E. J ensen, T. H. Hess, and A. L. Teel. 1999. Mechanism of the enhanced treatment of chloroaliphatic compounds by Fenton-like reactions. Environmental Science \& Technology 33:3432-3437.

Watts, R. J ., D. Washington, J . Howsawkeng, F. J . Loge, A. L. Teel. 2003. Comparative toxicity of hydrogen peroxide, hydroxyl radicals, and superoxide anion to Escherichia coli. Advances in Environmental Research 7:961-968.

World Health Organization. 2003. Guidelines for safe recreational water environments. Volume1. Coastal and Fresh Waters. Geneva, Switzerland. Available on-line: http://www.who.int/iris/handle/10665/42591.

Zhang, G. M., and I. Hua. 2000. Cavitation chemistry of polychlorinated biphenyls: decomposition mechanisms and rates. Environmental Science \& Technology 34:1529-1534. 


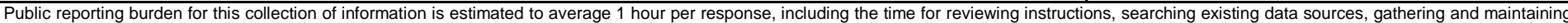

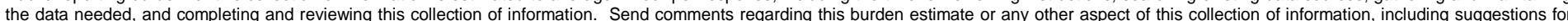

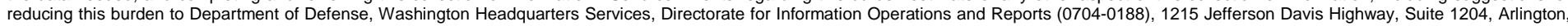

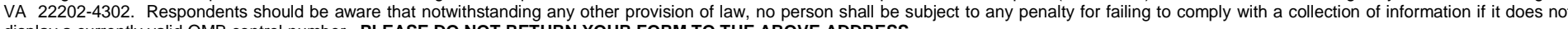
display a currently valid OMB control number. PLEASE DO NOT RETURN YOUR FORM TO THE ABOVE ADDRESS.

\begin{tabular}{l|l} 
1. REPORT DATE (DD-MM-YYYY) & 2. REPORT TYPE
\end{tabular}
February 2016

Final report

Testing of The KRIA Ionizing Water Treatment System for Waters Contaminated with Diesel, PCBs, and Nutrients (Nitrogen Forms)

\section{AUTHOR(S)}

Victor F. Medina, Agnes Morrow, Catherine C. Thomas, and Roy Wade

\section{TITLE AND SUBTITLE}

\section{DATES COVERED (From - To)}

5a. CONTRACT NUMBER

PM-0104046

5b. GRANT NUMBER

5c. PROGRAM ELEMENT NUMBER

5d. PROJECT NUMBER

5e. TASK NUMBER

5f. WORK UNIT NUMBER

8. PERFORMING ORGANIZATION REPORT NUMBER

ERDC/EL TR-16-3

Environmental Laboratory

3909 Halls Ferry Road

Vicksburg, MS 39180-6199

9. SPONSORING I MONITORING AGENCY NAME(S) AND ADDRESS(ES)
10. SPONSOR/MONITOR'S ACRONYM(S)

11. SPONSOR/MONITOR'S REPORT NUMBER(S)

\section{DISTRIBUTION I AVAILABILITY STATEMENT}

Approved for public release; distribution unlimited.

\section{SUPPLEMENTARY NOTES}

\section{ABSTRACT}

This project evaluated the KRIA water treatment system (also know under the trade name ECOSOAR) for treatment of three environmental contaminants: diesel fuel, PCBs (arochlor 1254) and nutrients (nitrogen forms). The KRIA water treatment system works by charging water with the superoxide radical $\left(\mathrm{O}_{2}^{-}\right)$, which is electrochemically generated from oxygen in the atmosphere. At the injection site, both cavitation and microbubble reactions may also occur. A review of the literature indicates that superoxide is a relatively weak radical, but it can work both oxidatively and reductively. A review of literature also showed that superoxide can transform chlorinated solvents and microcystin (a toxin associated with algae). Studies of the KRIA yielded promising results, but most of these studies lacked sufficient control to isolate variables, possibly casting doubt on the exact nature of the mechanism. Background studies were conducted to evaluate the KRIA's effect on water. The KRIA charged water for 135 minutes and was compared to a control in which the superoxide valve was turned off. It was found that the superoxide charging resulted in elevated (approximately threefold) levels of oxygen, which led to the water being supersaturated (by approximately 300\%). Conductivity was also increased, presumably due to the addition of charged oxygen species into the water. These elevated levels persisted for at least 24 hours after the charging, suggesting that the effect was persistent. The team also documented elevated concentrations of superoxide ion after charging. Treatment of diesel resulted in a 58\% increase in removal compared to the control reactor, and this was statistically significant. Treatment of PCBs resulted in a $20 \%$ increase in removal as compared to the control, and was also statistically significant. Treatment of nutrients (ammonia and nitrate) did not appear to result in any changes to their respective concentrations.

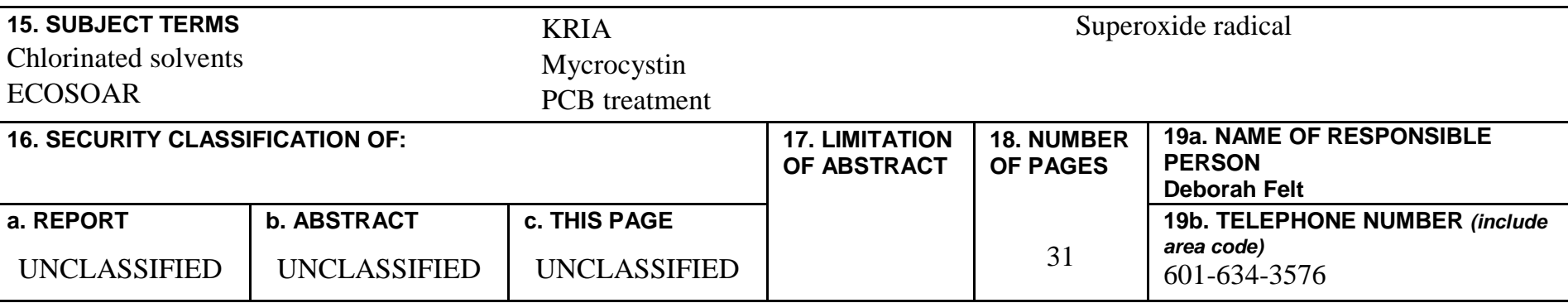

